\title{
CARLOS ALBERTO VESENTINI (1947 - 1990). IN MEMORIAM
}

\author{
Janice Theodoro da Silva ${ }^{1}$
}

Carlos Alberto Vesentini deixou-nos um legado admirável: sua escrita. A palavra, assim como a fotografia, reproduz a imagem, a voz, o pensamento daqueles que nos deixaram. Revirando seus artigos, livros, teses, papéis, procurei entender o que pode triunfar ao tempo.

Para reacender as lembranças do Professor Carlos Alberto Vesentini nada melhor, como ele mesmo dizia, do que "deixar o documento falar". Afinal Carlinhos era o artífice brasileiro da própria idéia de memória, que trabalhou num momento fecundo de sua carreira. Sua reflexão foi marcada por Jacques Le Goff, autor sempre citado em suas reflexões. Retomava-o para afirmar que a memória é feita de recordações e de esquecimentos, de manipulações conscientes e inconscientes que o interesse, a afetividade, o desejo, a inibição, a censura exercem sobre o indivíduo. Para ele a memória se assemelhava a um "conjunto de vestígios chamados recordações; uma consciência que procura caminhos, armada de vontade de edificar".

Compreender este nosso colega é debruçar-nos sobre sua vida e sua obra mas , não tão somente. Repetindo fragmentos do que ele deixou em seus papéis, parte pequena de nossas vidas é o que foi realizado ou publicado. Avaliar uma vida, ou ainda, lembrá-la, representa, sobretudo, recuperar perdas, as vezes doídas, pelas quais todos nós passamos. Uma vida é, mais ainda, tudo aquilo que excluímos de nossa história por receio ou dúvida, tudo que nos foi excluído, independentemente de nossa vontade, ou ainda, o que deixamos de ver, ofuscados que somos por sucessos circunstanciais. Serve ainda de referência para se construir uma memória aqueles alvos distantes que pretendíamos alcançar e 
que sempre, quando alcançados, tornam-se parte pequena de um enorme desejo. Ou ainda, os acidentes de percurso, capazes de alterar um projeto de vida desenhado com aparente harmonia e conviç̧ão. Tudo isto é, como ele nos lembrava, igualmente, vida.

Carlos Vesentini, biografado por si mesmo, selecionou, como marcos de sua história, o curso primário em Jaguapitã, norte do Paraná, a escola católica, no sistema de missa e catecismo diários. Sua formação ginasial foi completada em escola pública. Em Presidente Prudente, freqüentou dois cursos científico e técnico em contabilidade, na suposição, aparentemente lógica, de que serviria (contabilidade) para auxiliá-lo no mercado de trabalho. Sendo um dos cursos matinal e outro noturno, restava-1he as tardes para ajudar como caixa na loja de seus tios, que the proporcionaram a oportunidade de estudar em Prudente.

Pai bancário, dotado de imensa capacidade de sacrifício para que seus filhos estudassem, mãe plena de certeza no valor do estudo e partícipe do sacrifício; contou ele ainda com o apoio dos tios, que vincularam segurança e futuro a cursos onde houvesse matemática. Mas, todo este universo aparentemente estável foi abalado, fortemente, em 1968 e 1969. A falência de um banco obrigou a familia migrar e, em 69, Carlos Alberto Vesentini chegou a São Paulo. Neste mesmo ano frequentou o cursinho do grêmio, onde nos conhecemos. Como bancário atuou na oposição mas, a cada dia transcorrido, seu trabalho transforma-se em mera derivação das salas de aula.

Os livros, o saber, o conhecimento teve o poder de transformar toda uma vida marcada por uma rotina burocratizada. A formação religiosa deu colorido e profundidade aos textos lidos na Universidade, delineando a sua idéia de revolução. Idéia tão marcada pelo gênero romântico, capaz de se deixar confundir, como ele mesmo escreveu em seu memorial, com a valorização do coletivo ou ainda permitir consumir a idéia através da palavra, sacrifício: herança cristã. Cada dia mais sua vida ganhava um contorno político.

Carlos Alberto Vesentini decidiu-se pelo curso de História embora tivesse sido também aprovado em Ciências Sociais. Durante a graduação teve como companheiro de leitura e seminários, Alcir Lenharo, amigo de todas as horas. Stelia Bresciani foi, retomando palavras suas, "nossa mestra, plena de afinidade na vontade de avançar e Adalberto Marson, mestre e amigo, sempre capaz de despertar a "vontade de renovação."

Uma frase retirada de um escrito de J. L. Werneck da Silva marcou, para Carlos Vesentini , sua geração: 
R. História, São Paulo, n. 122, p. 129-133, jan/jul. 1990.

"... vimo-nos faltos de qualquer perspectiva, e estudar tornou-se estilo e meta, tendo a ciência ocupado o duplo papel de método e esperança. Politicamente em oposição ao regime, livres de qualquer doutrinamento (pela própria repressão), resistimos às condiçóes mesmas e à qualidade com que nossos cursos eram dados, estudando pesadamente".

Carlos Vesentini teve seu perfil acadêmico marcado por Marilena Chauí, Francisco Weffort e, especialmente, Fernando Novais. Participou ativamente dos seus seminários encontrando neles as referências necessárias a sua formação. Formação forjada, muitas vezes, em meio a dúvidas e angustias mas que, com passar dos anos, tornaram nítidas as diferenças aprofundando com elas o respeito ao seu antigo orientador.

O primeiro texto impresso, é sempre uma emoção: uma resenha, para a Revista de História . Redigida durante a sua graduação foi publicada por José Sebastião Witter que lhe abriu espaço chamando-o também para dar aulas conjuntas em seu curso sobre República.

A Revolução do Vencedor, texto elaborado em colaboração com Edgar de Decca, representou um momento de contacto com Gramsci, Hannah Arendt e Marilena Chauí. Não foram leituras acadêmicas, mas um "momento de revisão em meu modo de ser, em minha postura frente à vida".

Em 1977, dando continuidade as suas indagaçóes, Carlos Vesentini, observou 1964 como processo de legitimação de 1930, através de análises do texto de Ernesto Geisel. Este trabalho, A Fulguração Recorrente, foi publicado indicando amadurecimento no seu perfil de historiador. Enfocou mais em seu estudo a exclusão do que a dominação. Em 1978, escreve $O$ Problema do Sujeito Político, texto inédito. Maria Quitéria de Jesus: História e Cinema correspondeu, no seu próprio entender, "à superação de angustias." Fernando Novais orientou uma proposta de roteiro para um filme histórico e Alcir Lenharo incentivou-o diante dos temores que sempre precedem uma redação. O texto, repetindo suas palavras, conversou com Febvre.

Seu doutorado, A Teia do Fato: uma proposta de estudo sobre a memória histórica representou sua reflexão sobre o fato e a memória. Analisou o drama da interpretação nos mostrando os dispositivos através dos quais o fato, difundindo-se pelo conjunto social, une-se a uma lógica de compreensão da história. A metáfora da pedra, de que ele se utiliza para pensar o fato, é pedra de 
toque de sua vontade de liberdade. Libertar-se da memória, esquecer? Arrancar as raízes?

A partir de sua tese de doutorado, dedicou-se aos estudos sobre a relação entre fato e memória. Neste período, em meio ao trabalho intelectual, aprofundou sua amizade com Francisco Murari Pires." Graças ao seu trabalho" diz Vesentini, "pude aproximar a relação entre fato histórico e acontecimento, na forma como é composto na obra de Tucídides". Tucídides foi responsável por uma grande amizade daquelas que, feliz só se é, quando dela se encontra. A empresa destes dois amigos foi grande, arriscada, trabalhosa, representou ventura para ambos, ventura intelectual, ventura ao transpor o intransponível.

A vida docente de Carlos Alberto Vesentini iniciou-se em 1976, após convite do professor Fernando Novais. Entre 1980 e 1983, ministrou a disciplina Ásia e África. Entendia ele ser esta disciplina "a única do Departamento que poderia não aparecer vinculada ao peso da percepção da história privilegiadora da Europa, uma vez que - via história universal - aquelas sociedades localizadas no espaço físico da Asia e da África eram anteriores. Ou seja, elas apareciam como pré-Grécia, ou então a partir da expansão colonizadora européia. Portanto, a própria disciplina, ao lançar um apelo à Ásia e África, permitia entendê-las fora do contexto europeu." Sua forma de abordagem representava uma ruptura com o populismo e não foi posteriormente fácil, para ele, navegar contra a maré. A disciplina foi posteriormente extinta, o que levou Carlos Vesentini a dedicar-se à História contemporânea. Organizou cursos voltados para o século XX, aprofundando-se nos estudos sobre revolução. Aproximou às aulas ministradas às pesquisas, mergulhando no tema da democracia e da memória.

Em 1981, Vesentini, com um grupo de docentes, esforçou-se para barrar o projeto "Paulo Nathanael", que expurgava História e Geografia, implantando Estudos Sociais na escola secundária.

No Conselho Departamental, juntamente com Arnaldo Daraya Contier e Francisco Murari, Carlos Vesentini batalhou por mudanças. Etapa difícil, batalha inglória, que representou amadurecimento depois dos fracassos.

Entre 1985 e 1986, integrou a Comissão de Currículo do Departamento de História. Tempos de reforma, busca de uma reestruturação do Departamento. $\mathrm{Na}$ Comissão Curricular defendeu isonomia no trabalho docente e plena liberdade na proposição dos cursos. Mas, o essencial, como ele mesmo deixou escrito, foi o diálogo e o esforço conjunto com Francisco Murari Pires, de tal forma que 
ambos instrumentalizaram a mesma percepção do Departamento. Ao lado de ambos, partilhei também dela.

Seu último curso foi denso, rico, multiplicador de idéias. Era seu tesouro em termos de produção intelectual. Reservou-o para si e para seus alunos. Um curso sobre a memória, sobre o passado, sobre a razão, que nem sempre rege a vida, mas que o levou a refletir fundo para que muito dela ficasse contido em nossa memória.

Carlos Alberto Vesentini, nascido a 2 de maio de 1947, filho de Vitaliano Vesentini e Ana Balizardo Vesentini, amigo, colega, contemporâneo. Espero ter respondido com amor este desafio afetivo e intelectual. Compor sua memória, recompor com palavras fragmentos de uma vida "armada da vontade de edificar".

Mas, talvez, Drummond possa, melhor do que eu, com suas palavras, também sobreviventes, dizer mais, neste encontro em que procuramos reunir a família, os amigos, os colegas e os livros, companheiros fiéis, de Carlos Alberto Vesentini.

Por que nascemos para amar se vamos morrer?

Por que morrer, se amamos?

Por que falta sentido

ao sentido de viver, amar, morrer?

São Paulo, 31 de maio de 1990. 